Kcywords: ' 3 M' model; assessment; Australia; de Boer; Disaster Readiness Emergency Department (DRED) Score; emergency departments; preparedness, scoring system

Prebosp Disast Med 2002;17(s2):s65-66.

\section{Review of Disaster Preparedness of Australian Emergency Departments}

\section{Dr. Peter Aitken}

Australian Society for Emergency Medicine, Townsville General Hospital, Townsville, Queensland, Australia

Introduction: Emergency departments (ED) often are the first part of the health system to be affected in a disaster. How prepared are they?

Methods: This review was a prospective, postal survey distributed to the directors of all adult and mixed (adult and paediatric) Australian Emergency Departments. Those not accredited by the Australasian College for Emergency Medicine (ACEM) were excluded. Surveys were sent to 78 departments. Overall responses were reviewed, as were groupings by state, role delineation, annual attendances, hospital bed numbers, and access block. Actual disaster plan activation also was reviewed. The survey assessed all aspects of disaster preparedness from risk assessment and planning, to staffing, training, education, equipment, and funding. The impact of recent world events on preparedness was reviewed while departments also were asked to assess their own ability to manage disasters using a Likertlike scale.

Results: The response rate was $78 \%$. There was no significant difference in response rates between various states or various ACEM role delineations. There was a large variation in levels of disaster preparedness between departments. The majority had a reasonable level of planning, but provided limited education, training, or exercises. Those most prepared were those departments from New South Wales or Victoria with a Major Referral role. The Sydney Olympics had a significant effect on preparedness, but there was little correlation with previous disaster plan activation.

Keywords: education; emergency departments; equipment; exercises; funding; hospitals; management; planning; preparedness; risk assessment; staffing; training

Prebosp Disast Med 2002;17(s2):s66

\section{Findings of Health Reporting as Criteria of Preparedness in Emergencies}

\section{G.V.Kipor}

All-Russian Service for Disaster Medicine, "Zaschita", Moscow, Russia

Within last decade, the status of the public health system of Russia has changed drastically. The changes might be considered as a critical event for survival of state medical services and the new development of commercial medicine services.

This paper describes major tendencies of primary and integrated health characteristics of the population. For this purpose, an organization of public health services, methodology of health status assessment and situations in different regions of the European territory of Russia, its relationship to emergency medicine, and the criteria used for health system preparedness will be analyzed.
In public health and in disaster medicine, health monitoring is based on a large body of data that include parameters of activity of subordinated services as well as for the whole the system. This includes, first of all, hierarchical organization of initial statistical data collection, the subsequent transformation of the data into databases, data analysis, and presentation of output information.

Some approaches and conclusions of modern health monitoring methodology that serve as groups of basic indices for preparedness criteria elaboration and for decision-making include:

Group 1 - (a) Evaluation of demographic parameters and structure of population; (b) Evaluation of the health state dynamic in different sub-populations; (c) Evaluation of morbidity and mortality for specific diseases; and (d) Evaluation of causality of mortality. This group includes up to 36 basic integrated tables. Analysis of this group gives us basis for evaluation of health reserves capacities.

Group 2 - (a) Evaluation of resources and estimation of qualitative and quantitative parameters of public health system; and (b) Evaluation of general state and quantitative parameters of availability of medical, prophylactic and sanitary organizations, and the number of medical and nursery personnel. It includes indices of access of the Russian population to all kinds of medical services provided by the state public health system. This group includes 25 basic integrated tables. Analysis of this group gives us basis for evaluation of health system capacities and its potential applicability during emergencies.

Group 3 - Specific evaluation of parameters of availability of maternal and children services related to health indices for pregnant women, those for births, abortions, perinatal and fetal mortality, etc. This group includes nine integrated tables and gives us a basis for evaluation of specialized medical services in emergencies and their capacities in various emergency-prone regions.

Group 4 - Evaluation of medical and sanitary severity in emergency situations, resources of medical emergency services required for their permanent readiness. This group includes six integrated tables and provides a basis for preparedness evaluation of disaster medicine service.

Keywords: data; decision-making; development; disaster medicine; emergencies; evaluation; monitoring; preparedness; public health; Russia; services Prehosp Disast Med 2002;17(s2):s66.

\section{Description and Evaluation of Crash Program to Prepare Healthcare Professionals to Manage Casualties and to Instruct Their Colleagues Concerning Non-Conventional Warfare \\ Nela Marks, RN, BN; ${ }^{1}$ Robert Cohen, $P h D,{ }^{2}$ Lion Poles, $M D^{3}$ \\ 1. Ministry of Health, Department of Emergency, Israel. \\ 2. Center for Medical Education, Hebrew University Faculty of Medicine, Jerusalem, Israel \\ 3. Kaplan Medical Center and the Ministry of Health, Israel}

The possibility of a non-conventional attack on the State of Israel during 2003 encouraged the Emergency Services Department of the Ministry of Health to rapidly develop and implement an educational intervention to prepare healthcare professionals to deal with such an attack. This 